\title{
Assessment of intestinal permeability in preruminant calves by lactulose/mannitol test*
}

\author{
P. Klein ${ }^{1,3}$, J. Moravcová ${ }^{2}$, T. Kleinová ${ }^{1}$, Z. Volek ${ }^{1}$ \\ and V. Skřivanová1 \\ ${ }^{1}$ Research Institute of Animal Production \\ Praha-Uhrineves, CZ-104 01, Czech Republic \\ ${ }^{2}$ Department of Chemistry of Natural Compounds, Institute of Chemical Technology \\ Praha, CZ-166 28, Czech Republic
}

(Received 24 April 2006; revised version 10 July 2006; accepted 2 February 2007)

\begin{abstract}
The aim of this study was to utilize the lactulose/mannitol test for assessment of intestinal permeability (IP) in preruminant calves. IP was increased experimentally by administration of Indomethacin. Both sugar markers were determined simultaneously as silyl-derivates in $5 \mathrm{~h}$ urinary production using the gas liquid chromatography technique. The index of IP was determined as the ratio between urinary recovery (\%) of $10 \mathrm{~g}$ lactulose to $5 \mathrm{~g}$ D-mannitol. The IP index in control calves was $0.242 \pm 0.048$. Doses of 20 and $60 \mathrm{mg}$ Indomethacin did not significantly affect IP, but the IP index was significantly enhanced in calves receiving $120 \mathrm{mg}$ of drug $(0.541 \pm 0.091 ; \mathrm{P}<0.01)$. Results of this study show that ratio of lactulose to D-mannitol in urine reflected the treatment by the highest dose of Indomethacin and that the test may be used for determination of IP in preruminant calves.
\end{abstract}

KEY WORDS: intestinal permeability, calves, lactulose/mannitol test, gas liquid chromatography, Indomethacin

\section{INTRODUCTION}

The small intestine plays an important role as the protective barrier between external and internal environment of the organism. Failure of this barrier has great impact on the etiology and pathogenesis of many intestinal diseases. This condition is characterized primarily by higher paracelullar permeability for macromolecules (Gasbarini and Montalto, 1999).

\footnotetext{
* Supported by the Ministry of Agriculture of the Czech Republic, Project MZe-000 2701403

${ }^{3}$ Corresponding author: e-mail: klein.pavel@vuzv.cz
} 
Paracellular permeability of the small intestine may be measured by a simple, noninvasive test based on the simultaneous peroral administration of two molecules of different size such a monosaccharide (e.g., L-rhamnose) or alditol (e.g., D-mannitol), and disaccharide (e.g., lactulose or cellobiose) or ${ }^{51} \mathrm{Cr}$-EDTA. The principle of the test is based on assumption that 2 types of pores of different size, and differentially permeable to small and large probes, are present in the intestinal mucosa (Hall, 1999). The probes passing through large pores havemolecularradiusup to $0.5 \mathrm{~nm}$, whereasmolecularradius of the probes passing through small pores is equal or less than $0.4 \mathrm{~nm}$ (Bjarnason et al., 2002). Some authors note even 3 types of pores in intestinal epithelia: 1 . small pores up to $0.6 \mathrm{~nm}$ localized on the tips of the villi which are permeable only to monosoccharides and alditols, 2. large pores $(5-6 \mathrm{~nm})$ permeable to disccharides are localized in the crypts, and 3. the medium-sized pores $(1-1.5 \mathrm{~nm})$ are localized at the base of the villi (Melichar et al., 2005).

The mechanism predominantly responsible for transepithelial movement of monosaccharides is solvent drag originating from the hyperosmolarity of the villi tips (Melichar et al., 2005), whereas disaccharides pass intestinal mucosa paracellulary, by tight junctions. The paracellular transport is passive and results from diffusion, electrodiffusion, or osmosis down the gradients created by transcellular mechanisms (Anderson, 2001). The paracellular transport increases with intensity of damage of the mucosa, while absorption of small probes is affected mostly by reduction of the absorption surface (Hall, 1999). The ratio between recovery of large and small probe, usually examined in 4-6 h urine production, is therefore interpretable as the index of intestinal permeability, and provides information on the integrity of the gut mucosa.

Intestinal permeability (IP) tends to be higher in humans with Crohn's disease (Püspök et al., 1998), coeliacal sprue (Vogelsang et al., 1998), or ulcerative colitis (Miki et al., 1998). IP may also be enhanced with some chemical or physical stimuli, long-time fasting, exercise (Pals et al., 1997), following the administration of non-steroid antiinflammatory drugs (Suenaert et al., 2000; Gotteland et al., 2001) or alcohol (Napolitano et al., 1995). IP is also enhanced by the exposure to $\gamma$-radiation, mainly during abdominal or pelvic rtg-examination (Pia de la Maza et al., 2001). In veterinary practice this test has been used for diagnosis of glutensensitive enteropathy in dogs (Hall, 1999). Similarly Branco Pardal et al. (1995) used IP test with sugar probes for assessment of the intestinal response on feeding of milk replacer with antigenic soyabean concentrate. In addition, authors of this study found that low sucrase activity in the small intestine of calves allows the use sucrose as a large-sized probe with similar results as obtained with laculose.

The applicability and sensitivity of IP tests in both humans and animals can be evaluated experimentally. Fasting and experimentally induced abdominal burn injury was used in rats (Pernet et al., 1998). In human volunteers, IP was 
experimentally enhanced, e.g., with endotoxin (O'Dwyer et al., 1988) or by nonsteroidal antiinflammatory drugs such as Indomethacin (Suenaert et al., 2000; Gotteland et al., 2001).

The aim of present study was to utilize the lactulose/mannitol test in preruminant calves for measurement of their intestinal permeability (IP). The IP in calves was experimentally elevated by administration of 3 different doses of Indomethacin.

\section{MATERIAL AND METHODS}

\section{Animals and experimental design}

Experiments were carried out on 24 clinically healthy male Holstein calves 10 days ( $\pm 36 \mathrm{~h}$ ) of age. All animals were obtained from the same dairy farm and weighed from 40.5 to $44.5 \mathrm{~kg}$. Calves received colostrum for four days after the birth, then were switched to raw bovine milk to provide natural feed throughout the study.

Calves were randomly allocated into four groups, six in each: control (I), $20 \mathrm{mg}$ (II), $60 \mathrm{mg}$ (III) and $120 \mathrm{mg}$ (IV) of Indomethacin (IM; Sigma-Aldrich, Praha, Czech Republic). The dose of IM was divided into 2 equal portions and administered perorally in gelatin capsule. One half of the dose was administered together with the evening meal. After $9 \mathrm{~h}$, the second part of IM was administered. Three $h$ later all animals were individually penned in narrow plastic boxes and test was performed following the protocol mostly used in humans (e.g., Vogelsang et al., 1998): calves received a solution of $5 \mathrm{~g}$ D-mannitol (Lachema, Neratovice, Czech Republic) and $10 \mathrm{~g}$ lactulose (Duphalac $\AA$, Solvay Pharmaceuticals, Wheesp, The Netherlands) in $100 \mathrm{~mL}$ of distilled water. After administration of the solution, urine was collected for 5 consecutive $\mathrm{h}$ using urine bags. Collection bags were fixed onto the body with adhesive tape and urine was drained with a polypropylene tube into a bottle cooled in an external water bath. A solution of $10 \%$ thymol in isopropyl alcohol (both Lachema, Neratovice, Czech Republic) was used to avoid microbial degradation of the markers as described by Osborne (1995). During the test the animals were allowed to drink water aromatized with a few drops of chamomile extract to ensure sufficient urine production. Urine volume was measured and $100 \mathrm{~mL}$ aliquots were stored at $-28^{\circ} \mathrm{C}$ until analysis.

\section{Analysis of samples}

Sample preparation. Five hundred microliters of urine or standard solution (D-mannitol, $0.301 \mathrm{mmol} \cdot \mathrm{L}^{-1}$, Lachema, Neratovice, Czech Republic; lactulose, $0.129 \mathrm{mmol} \mathrm{L}^{-1}$, Sigma-Aldrich, Praha, Czech Republic) were placed into a 
silylation tube and $20 \mu \mathrm{L}$ of solution of xylitol (internal standard, $7.887 \mathrm{mmol} \cdot \mathrm{L}^{-1}$, Lachema, Neratovice, Czech Republic) was gently added. Standards and internal standards were prepared using distilled water. Water was then evaporated in a vacuum desiccator using $\mathrm{NaOH}$ as a drying agent. Next, each vial was sealed with a screw cap and $30 \mu \mathrm{L}$ anhydrous pyridine, $10 \mu \mathrm{L}$ hexamethyldisilazane (both Lachema, Neratovice, Czech Republic) and $10 \mu \mathrm{L}$ trimethylchlorosilane (SigmaAldrich, Praha, Czech Republic) were inserted through a septum. The reactions were kept overnight at room temperature and the vials were continuously and gently shaken. Finally, $0.5 \mu \mathrm{L}$ of clear supernatant was injected directly into the chromatographic system.

GLC conditions. Analyses were performed with the Hewlett-Packard 5890 A gas chromatography instrument equipped with a flame-ionization detector. A fused silica capillary column $(50 \mathrm{~m} \times 0.20 \mathrm{~mm}$ I.D. $)$ with chemically bonded cross-linked methyl silicone (film thickness $0.33 \mu \mathrm{m}$ ) was used with nitrogen as a carrier gas at a flow rate of $1.2 \mathrm{~mL} \cdot \mathrm{min}^{-1}$ (split 1:50). Temperature: detector, $230^{\circ} \mathrm{C}$ and injector, $200^{\circ} \mathrm{C}$. Column temperature was programmed as follows: $120^{\circ} \mathrm{C}(1 \mathrm{~min}), 15^{\circ} \mathrm{C}$. $\mathrm{min}^{-1}$ to $230^{\circ} \mathrm{C}, 8^{\circ} \mathrm{C} \cdot \mathrm{min}^{-1}$ to $320^{\circ} \mathrm{C}, 320^{\circ} \mathrm{C}(10 \mathrm{~min})$. The following retention times were obtained: lactulose, $24.94 \mathrm{~min}$; D-mannitol, $16.67 \mathrm{~min}$; xylitol, $13.94 \mathrm{~min}$. Each analysis was performed twice. Trimethylsilylated analytes were quantified by measuring the area under the respective peak using the response factor obtained with standard solutions. The concentration of the sugars in urine was derived from the ratio of the test samples to the internal standard.

\section{Statistical analysis}

Index of IP was calculated as the ratio of lactulose/D-mannitol recoveries during a $5 \mathrm{~h}$ urine collection period. One-way ANOVA and Scheffé's multiple range test were used for the statistical analysis of IP indexes. The relationship between excretion of lactulose and D-mannitol was evaluated using regression analysis. The statistical package QC Expert, version 2.5 (TriloByte ${ }^{\circledR}$ Ltd, Pardubice, Czech Republic) was used.

\section{RESULTS}

The $5 \mathrm{~h}$ urine production in calves varied from 220 to $1740 \mathrm{~mL}$. Urine samples taken prior to marker administration were negative for presence of both Dmannitol and lactulose suggesting that diet of calves did not contain these sugars or their sources. In all animals the excretion of both sugar markers was tightly correlated (Figure 1). The IP index was not significantly affected by $20 \mathrm{mg}$ (IP index $=0.255 \pm 0.060$ ) and $60 \mathrm{mg}$ (IP index $=0.270 \pm 0.082$ ) of Indomethacin, as 


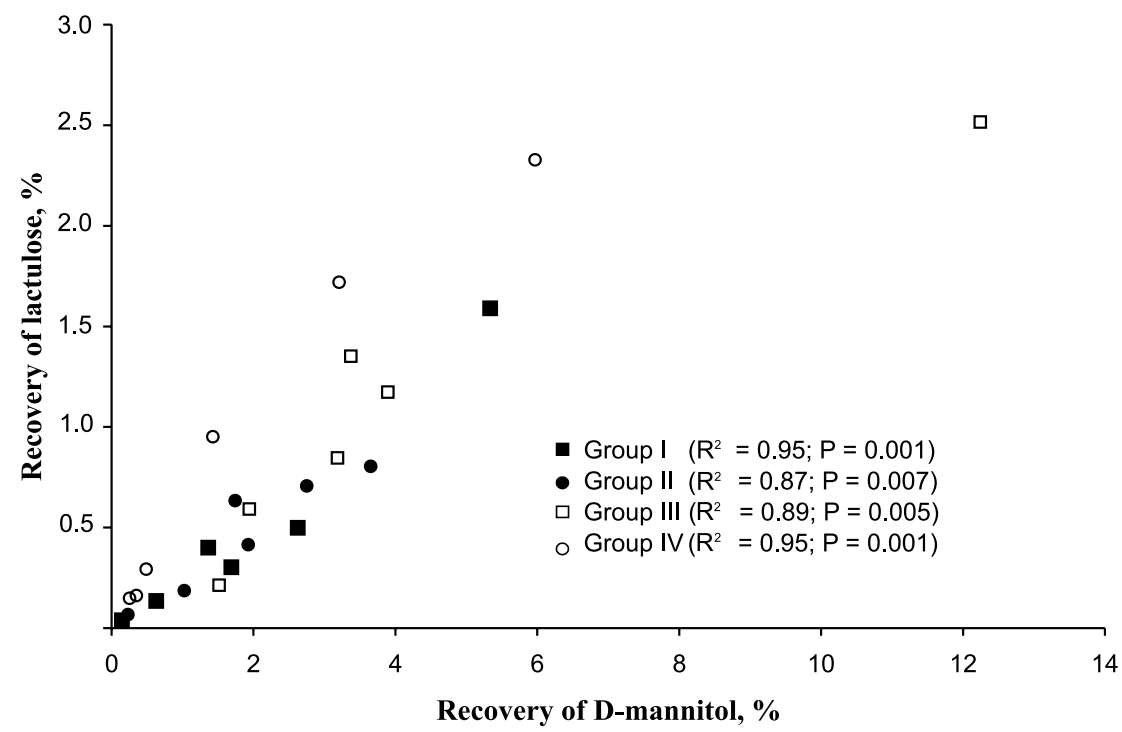

Figure 1. Relationship between exrection of D-mannitol and lactulose in $5 \mathrm{~h}$ urine samples from preruminant calves. Experimental groups were orally administrated doses of 0 (group I), 20 (group II), 60 (group III) and 120 (group IV) mg of Indomethacin per animal

compared to control animals (IP index $=0.242 \pm 0.048$ ). In contrast, a significant $(\mathrm{P}<0.01)$ enhancement of IP (IP index $=0.541 \pm 0.091)$ was observed with the highest dose of $120 \mathrm{mg}$ IM (Figure 2).

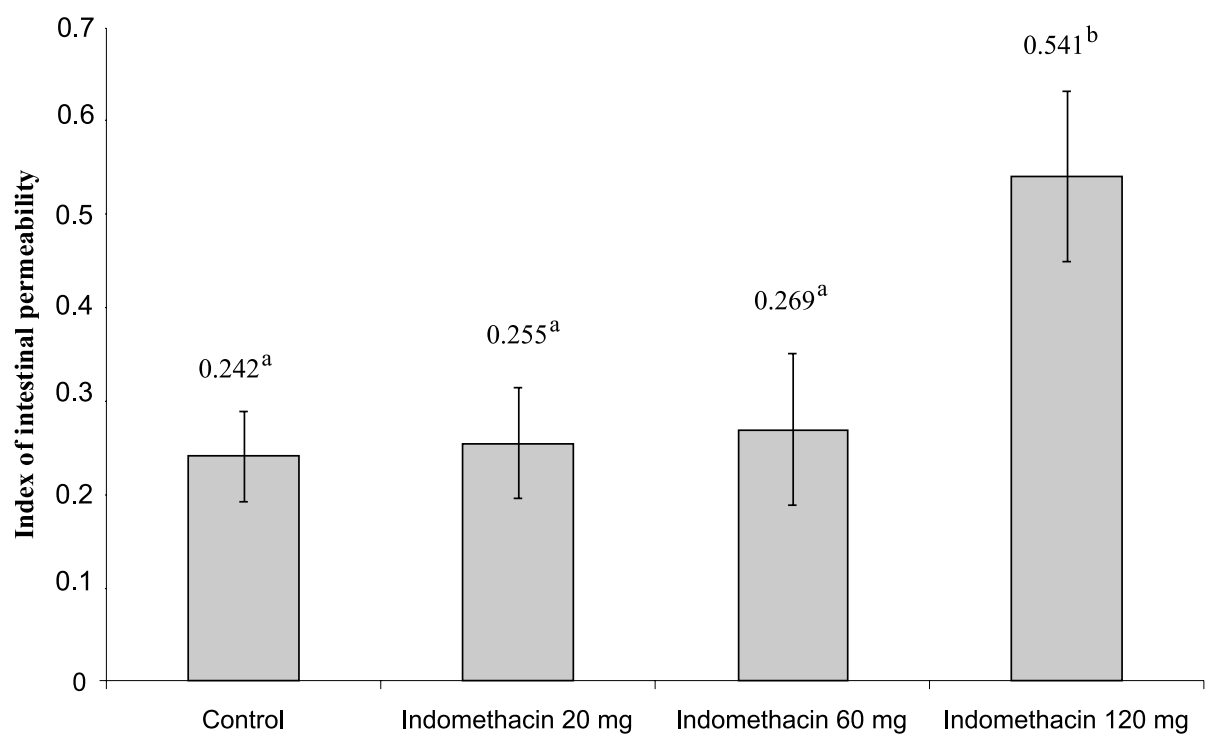

Figure 2. IP index calculated from $5 \mathrm{~h}$ urine samples from calves following oral administration of $0,20,60$ and $120 \mathrm{mg}$ of Indomethacin per head. Values a,b differ significantly at $\mathrm{P}<0.01$ 


\section{DISCUSSION}

The GLC method for the determination of trimethylsilyl ethers of lactulose and D-mannitol was slightly modified from that of Dumas et al. (1994). In the our modification, the silylation was carried out at ambient temperature and xylitol was used as internal standard for both analytes. Although retention times on methyl silicone stationary phase were longer than those published, column efficiency was sufficiently high allowing the separation of D-glucose from D-mannitol. The relative standard deviation (RSD) for D-mannitol and lactulose were 5.48 and $11.14 \%$, respectively. In comparison, the published RSDs for the determination of D-mannitol and lactulose in human urine were 8.9 and $9.3 \%$ (Dumas et al., 1994).

Some details of the pathogenesis of IM-induced enteropathy are still uncertain. IM is a potent inhibitor of cyclooxygenase, both constitutive COX-1 and inducible COX-2 isoforms, which are responsible for prostanoids synthesis in tissues (Vane et al., 1998). It is assumed that whereas inhibition of COX-2 leads to supression of inflammation, drug inhibition of COX-1 is responsible for functional and structural alterations in the gastro-intestinal mucosa, if drug is ingested (Brooks et al., 1999). Nevertheless, this cyclooxygenase inhibition does not fully explain pathogenesis of the drug-induced enteropathy. The second mechanism involves specific biochemical damage to mitochondria, with uncoupling of oxidative phosphorylation reaction and calcium release into cytosol, which in turn cause secondary biochemical damage of enterocytes resulting to increased IP (Leite et al., 2004).

Although IM is widely used model of enteropathy, to our knowledge, it was never used for this purpose in calves. The doses commonly used in laboratory animals, e.g., $7.5 \mathrm{mg} \cdot \mathrm{kg}^{-1}$ (Leite et al., 2004), $10 \mathrm{mg} \cdot \mathrm{kg}^{-1}$ (Anthony et al., 1997) or $15 \mathrm{mg} \cdot \mathrm{kg}^{-1}$ (Kelly et al., 1998) are much higher than the dosage in our experiment (approximately $0.5-3 \mathrm{mg} \cdot \mathrm{kg}^{-1}$ ), since the aim of these studies was to induce macroscopic lesions in the GIT mucosa, such as ulceration. In contrast, in study of Suenaert et al. (2000) on human volunteers the drug at a dose of 125 was administered only in order to increase IP. Thus, the doses of IM as well as the route of drug administration in our experiment were based on the design of these human studies, taking into account the weight difference between calves and adult humans. Interestingly, the significant elevation of IP indexes in calves was observed only at the highest dose of drug. On the other hand, it is necessary to note that a final harmful effect of NSAID depends on many other factors. Results of this study with a limited number of subjects can not be generalized.

Results of our study demonstrate that design of the lactulose/mannitol test as used in humans is also applicable to calves. In comparsion with other mammalian 
species, the urinary recovery of D-mannitol and lactulose in calves was more variable. In one calf (group III) the recovery of D-mannitol was as high as $12.24 \%$, but the IP index was in the normal range $(0.205)$ due to a high lactulose recovery (2.51\%). In other animals, recoveries varied from 0.15 to $5.97 \%$ for D-mannitol, and from 0.04 to $2.33 \%$ for lactulose. In spite of this variability, excretion of lactulose highly correlated with excretion of D-mannitol (Figure 1), suggesting that both probes are affected equally by nonmucosal factors (Hall, 1999; Bjarnason et al., 2002), and that the test is reliable in calves.

To this date only one report on the assessment of IP with the lactulose/ mannitol test in calves has been published (Branco Pardal et al., 1995). Results of this study showed that the IP index in 6-8 week-old calves calculated from $6 \mathrm{~h}$ urine recoveries varied from 1.43 to 2.28 . Our findings are approximately 5-10 times lower and comparable with those described for adult rats (Pernet et al., 1998) or adult cats (Papasouliotis et al., 1993). Interestingly, our results are also comparable with those obtained in neonatal humans (van Elburg et al., 2003).

The observed difference may come from different physiological conditions and from the methodology used in this study. Firstly, substantial effect may be assigned to diet. The calves in our study were fed by bovine milk to provide a natural diet throughout the study, whereas animals in study of Branco Pardal et al. (1995) were fed on a diet containing components of plant origin. The plantderived proteins are unnatural for suckling calves and may exert harmful effects on the intestinal epithelia. The harmful effect of feeding soyabean products with high content in antigenic components to preruminant calves was found to be responsible for impaired intestinal functions and digestive disorders (e.g., Lalles et al., 1998). On the other hand, Branco Pardal et al. (1995) present also results of experiment where IP in calves was measured using the sucrose/mannitol test. The IP indeces expressed as this ratio varied from 0.59 to 1.23 , and no significant effect of diet on elevation of IP was observed among groups fed skimmed milk, or antigenic and nonantigenic soyabean protein concentrate.

The age of the animals and inferential physiological differences may be also important. In newborns having both a structurally and functionally immature intestine, other non-specific transport mechanisms, such as transport via apical canalicular system (ACS) can play crucial role in the age-related differences in absorptive processes (Baintner, 2002). On the other hand, the mean age of calves in our study was 10 days, whereas the biggest differences in transepithelial transport in the intestine of ruminants are found immediately after birth. Intestinal closure in calves occurs after $32 \mathrm{~h}$ of age (Stott et al., 1979). The transport via ACS is typical for immature intestinal mucosa and plays a key role in the absorption of macromolecules such as colostral immunoglobulines necessary for passive immunization of youngs. Moreover ACS probably also plays some role in transepithelial transport of vitamins 
and minerals (Baintner, 1986, 2002). A possible effect of this transport route on the uptake of saccharides such as lactulose and D-mannitol is nevertheless still uncertain. These differences, if any, seem to be responsible for different values of the IP index between neonatal and adult individuals of the same species, and they probably do not affect the principle of the dual sugar permeability test as shown for instance in human neonates (van Elburg et al., 2003). Results of the same study, moreover, shows that IP in human neonates is significantly affected not only by age, but also by other factors such as time since the first milk intake, by feeding with human vs bovine milk, or by gestation time.

Finally, differences among both studies on calves were also in the methodology. As required for humans, we delivered the markers in distilled water after overnight fasting (Vogelsang et al., 1998) to eliminate effects of osmotically active intermediates of digestion on the transepithelial transport of markers. In contrast, Branco Pardal et al. (1995) administered the markers together with food. In human subjects it was found that ingestion of hyperosmolar solutions $\left(>1.5 \mathrm{osm} \cdot \mathrm{L}^{-1}\right)$ cause significant temporary increase of IP to the large probes (Bjarnason et al., 2002). The urinary recovery of D-mannitol in our study (0.155.97\%) was of similar magnitude as found by Branco Pardal et al. (1995), whereas the difference among both studies comes just from a lower recovery of laculose in our experiment. This finding indicates that the source of this difference can be found in the experimental methodology.

Further investigations on a large number of animals of different age and carried out under different physiological conditions are therefore necessary to establish the reference range of the IP index in calves.

\section{CONCLUSIONS}

The lactulose/mannitol test assessing paracellular permeability of the small intestine is a simple, cheap, and non-invasive diagnostic tool giving information on the integrity of the mucosa and on its protective barrier function. Results of this experiment shows that this test is usable also in preruminant calves giving IP index values in healthy animals of about 0.25 below those obtained with the same methodology as widely used in human gastroenterology. In contrast, a more than $100 \%$ elevation of IP was observed in calves treated by $120 \mathrm{mg}$ of enterotoxic drug Indomethacin.

Since increased IP predates macroscopic mucosal damage, this test may help to predict negative responses of the intestine to many potentially harmful stimuli and thus serve in physiological, pharmaceutical and particularly in nutritional research focused on the youngest age group of this important farm animal. 


\section{REFERENCES}

Anderson J.M., 2001. Molecular structure of tight junctions and their role in epithelial transport. News Physiol. Sci. 16, 126-130

Anthony A., Pounder R.E., Dhillon A.P., Wakefield A.J., 1997. Vascular anatomy defines sites of indomethacin induced jejunal ulceration along the mesenteric margin. Gut 41, 763-770

Baintner K., 1986 (Editor). Intestinal Absorption of Macromolecules. CRC Press, Boca Raton, pp. 54-55

Baintner K., 2002. Vacuolation in the young. In: R. Zabielski, P.C. Gregory, B. Weström (Editors). Biology of the Intestine in Growing Animals. Elsevier Science, Amsterdam, pp. 55-110

Bjarnason I., Cedeborg A., Akvist A., Smale S., 2002. Intestinal barrier function. In: R. Zabielski, P.C. Gregory, B. Weström (Editors). Biology of the Intestine in Growing Animals. Elsevier Science, Amsterdam, pp. 657-693

Branco Pardal P., Lalles J.P., Andre F., Delval E., Toullec R., 1995. Assessment of gastrointestinal permeability to small marker probes in the preruminant calf. Reprod. Nutr. Develop. 35, 189-200

Brooks P., Emery P., Evans J.F., Fenner H., Hawkey C.J., Patrono C., Smolen J., Breedveld F., Day R., Dougados M., Ehrich E.W., Gijon-Banos J., Kvien T.K., Van Rijswijk M.H., Warner T., Zeidler H., 1999. Interpreting the clinical significance of the differential inhibition of cyclooxygenase-1 and cyclooxygenase-2. Rheumatology (Oxford) 38, 779-788

Dumas F., Aussel C., Pernet P., Martin C., Giboudeau J., 1994. Gas chromatography applied to the lactulose-mannitol intestinal permeability test. J. Chromatogr. B 654, 276-281

Gasbarrini G., Montalto M., 1999. Structure and function of tight junctions. Role in intestinal barrier. Ital. J. Gastroenterol. Hepatol. 31, 481-488

Gotteland M., Cruchet Verbeke S., 2001. Effect of Lactobacillus ingestion on the gastrointestinal mucosal barrier alterations induced by indometacin in humans. Aliment. Pharmacol. Therapeut. $15,11-17$

Hall E.J., 1999. Clinical laboratory evaluation of small intestinal function. Vet. Clin. N. Amer.Small. Anim. 29, 441-469

Kelly D.A., Piasecki C., Anthony A., Dhillon A.P., Pounder R.E., Wakefield A.J., 1998. Focal reduction of villous blood flow in early indomethacin enteropathy: a dynamic vascular study in the rat. Gut 42, 366-373

Lalles J.P., Duvaux-Ponter C., Sissons J.W., Toullec R., 1998. Small intestinal motility disorders in preruminant calves chronically fed a diet based on antigenic soya: characterization and possible mediators. Vet. Res. 29, 59-72

Leite A.Z., Sipahi A.M., Damiao A.O., Garcez A.T., Buchpiguel C.A., Lopasso F.P., Lordello M.L., Agostinho C.L., Laudanna A.A., 2004. Effect of a selective nonsteroidal anti-inflammatory inhibitor of cyclooxygenase-2 on the small bowel of rats. Braz. J. Med. Biol. Res. 37, 333-336

Melichar B., Dvorak J., Hyspler R., Zadak Z., 2005. Intestinal permeability in the assessment of intestinal toxicity of cytotoxic agents. Chemotherapy 51, 336-338

Miki K., Moore D.J., Butler R.N., Southcott E., Couper R.T., Davidson G.P., 1998. The sugar permeability test reflects disease activity in children and adolescents with inflammatory bowel disease. J. Pediatr. 133, 750-754

Napolitano L.M., Koruda M.J., Zimmerman K., McCowan J., Chang Meyer A.A., 1995. Chronic ethanol intake and burn injury: evidence for synergistic alteration in gut and immune integrity. J. Trauma 38, 198-207

O‘Dwyer S.T., Michie H.R., Ziegler T.R., Revhaug A., Smith R.J., Wilmore D.W., 1988. A single dose of endotoxin increases intestinal permeability in healthy humans. Arch. Surg. 123, 14591464 
Osborne C.A., 1995. Techniques of urine collection and preservation. In: C.A. Osborne, D.R. Finco (Editors). Canine and Feline Nephrology and Urology. Lippincott, Williams \& Wilkins, Philadelphia, pp. 100-121

Pals K.L., Chang R.T., Ryan A.J., Gisolfi C.V., 1997. Effect of running intensity on intestinal permeability. J. Appl. Physiol. 82, 571-576

Papasouliotis K., Gruffydd-Jones T.J., Sparkes A.H., Cripps P.J., Millard W.G., 1993. Lactulose and mannitol as probe markers for in vivo assessment of passive intestinal permeability in healthy cats. Amer. J. Vet. Res. 54, 840-844

Pernet P., Aussel C., Le Boucher J., Giboudeau J., Cynober L., Coudray-Lucas C., 1998. Standardization of the lactulose-D-mannitol test in rats: application to burn injury. Eur. Surg. Res. 30, 69-76

Pia de la Maza M., Gotteland M., Ramirez C., Araya M., Yudin T., Bunout D., Hirsch S., 2001. Acute nutritional and intestinal changes after pelvic radiation. J. Amer. Coll. Nutr. 20, 637-642

Püspök A., Oberhuber G., Wyatt J., Maier-Dobersberger T., Hammer J., Pfeffel F., Wrba F., Potzi R., Vogelsang H., 1998. Gastroduodenal permeability in Crohn's disease. Eur. J. Clin. Invest. $28,67-71$

Stott G.H., Marx D.B., Menefee B.E., Nightengale G.T., 1979. Colostral immunoglobulin transfer in calves I. Period of absorption. J. Dairy Sci. 62, 1632-1638

Suenaert P., Bulteel V., Den Hond E., Hiele M., Peeters M., Monsuur F., Ghoos Y., Rutgeerts P., 2000. The effects of smoking and indomethacin on small intestinal permeability. Aliment. Pharmacol. Therapeut. 14, 819-822

van Elburg R.M., Fetter W.P., Bunkers C.M., Heymans H.S., 2003. Intestinal permeability in relation to birth weight and gestational and postnatal age. Arch. Dis. Child. 88, F52-55

Vane J.R., Bakhle Y.S., Botting R.M., 1998. Cyclooxygenases 1 and 2. Annu. Rev. Pharmacol. Toxicol. 38, 97-120

Vogelsang H., Schwarzenhofer M., Oberhuber G., 1998. Changes in gastrointestinal permeability in celiac disease. Digest. Dis. 16, 333-336 